\title{
Soret and Dufour Effects on Natural Convection Flow Past a Vertical Surface in a Porous Medium with Variable Viscosity
}

\author{
M. B. K. Moorthy ${ }^{1}$ and K. Senthilvadivu² \\ ${ }^{1}$ Department of Mathematics, Institute of Road and Transport Technology, Erode, Tamilnadu 638316, India \\ ${ }^{2}$ Department of Mathematics, K. S. Rangasamy College of Technology, Tiruchengode, \\ Tamilnadu 637215, India
}

Correspondence should be addressed to K. Senthilvadivu, senthilveera47@rediffmail.com

Received 25 July 2011; Accepted 1 November 2011

Academic Editor: Elsayed M. E. Zayed

Copyright (c) 2012 M. B. K. Moorthy and K. Senthilvadivu. This is an open access article distributed under the Creative Commons Attribution License, which permits unrestricted use, distribution, and reproduction in any medium, provided the original work is properly cited.

\begin{abstract}
The heat and mass transfer characteristics of natural convection about a vertical surface embedded in a saturated porous medium subject to variable viscosity are numerically analyzed, by taking into account the diffusion-thermo (Dufour) and thermal-diffusion (Soret) effects. The governing equations of continuity, momentum, energy, and concentrations are transformed into nonlinear ordinary differential equations, using similarity transformations, and then solved by using RungeKutta-Gill method along with shooting technique. The parameters of the problem are variable viscosity, buoyancy ratio, Lewis number, Prandtl number, Dufour effect, Soret effect, and Schmidt number. The velocity, temperature, and concentration distributions are presented graphically. The Nusselt number and Sherwood number are also derived and discussed numerically.
\end{abstract}

\section{Introduction}

Coupled heat and mass transfer by natural convection in a fluid-saturated porous medium has received great attention during the last decades due to the importance of this process which occurs in many engineering, geophysical, and natural systems of practical interest such as geothermal energy utilization, thermal energy storage, and recoverable systems and petroleum reservoirs. A comprehensive account of the available information in this field is provided in recent books by Pop and Ingham [1], Ingham and Pop [2], and Vafai [3].

The previous studies, dealing with the transport phenomena of momentum and heat transfer, have dealt with one-component phases which posses a natural tendency to reach equilibrium conditions. However, there are activities, especially in industrial and chemical engineering processes, where a system contains two or more components whose concentrations vary from point to point. In such a system, there is a natural tendency for 
mass to be transferred, minimizing the concentration differences within the system and the transport of one constituent, from a region of higher concentration to that of a lower concentration. This is called mass transfer.

When heat and mass transfer occurs simultaneously between the fluxes, the driving potential is of more intricate nature, as energy flux can be generated not only by temperature gradients but by composition gradients as well. The energy flux caused by a composition gradient is called the Dufour or diffusion-thermo effect. Temperature gradients can also create mass fluxes, and this is the Soret or thermal-diffusion effect. Generally, the thermaldiffusion and the diffusion-thermo effects are of smaller-order magnitude than the effects prescribed by Fourier's or Fick's laws and are often neglected in heat and mass transfer processes. There are, however, exceptions. The Soret effect, for instance, has been utilized for isotope separation, and in mixtures between gases with very light molecular weight $\left(\mathrm{H}_{2}, \mathrm{He}\right)$. For medium molecular weight $\left(\mathrm{N}_{2}\right.$, air), the Dufour effect was found to be of a considerable magnitude such that it cannot be neglected (Eckert and Drake) [4].

Kassoy and Zebib [5] studied the effect of variable viscosity on the onset of convection in porous medium. Cheng and Minkowycz [6] studied the effect of free convection about a vertical plate embedded in a porous medium with application to heat transfer from a dike. Bejan and Khair [7] studied the buoyancy-induced heat and mass transfer from a vertical plate embedded in a saturated porous medium. Lai and Kulacki [8] studied the coupled heat and mass transfer by natural convection from vertical surface in a porous medium. The same authors [9] also studied the effect of variable viscosity on convection heat transfer along a vertical surface in a saturated porous medium. Elbashbeshy and Ibrahim [10] investigated the effect of steady free convection flow with variable viscosity and thermal diffusivity along a vertical plate. Kafoussias and Williams [11] studied the thermal-diffusion and diffusion-thermo effects on the mixed free-forced convective and mass transfer steady laminar boundary layer flow, over a vertical plate, with temperature-dependent viscosity. Yih [12] analyzed the coupled heat and mass transfer in mixed convection about a wedge for variable wall temperature and concentration. Jumah and Mujumdar [13] studied the coupled heat and mass transfer for non-Newtonian fluids. Anghel et al. [14] investigated the Dufour and Soret effects on free convection boundary layer over a vertical surface embedded in a porous medium. Kumari [15] analyzed the effect of variable viscosity on free and mixed convection boundary layer flow from a horizontal surface in a saturated porous medium. Postelnicu et al. [16] investigated the effect of variable viscosity on forced convection over a horizontal flat plate in a porous medium with internal heat generation. Seddeek [17], Seddeek and Salem [18] studied the effects of chemical reaction, variable viscosity, and thermal diffusivity on mixed convection heat and mass transfer through porous media. Ali [19] studied the effect of variable viscosity on mixed convection along a vertical plate. Alam et al. [20] analyzed the study of the combined free-forced convection and mass transfer flow past a vertical porous plate in a porous medium with heat generation and thermal diffusion. Pantokratoras [21] analyzed the effect of variable viscosity with constant wall temperature. Partha et al. [22] looked for the effect of double dispersion, thermal-diffusion, and diffusion-thermo effects in free convection heat and mass transfer in a non-Darcy electrically conducting fluid saturating a porous medium. Alam and Rahman [23] studied the Dufour and Soret effects on mixed convective flow past a vertical porous plate with variable suction. Seddeek et al. [24] studied the effects of chemical reaction and variable viscosity on hydromagnetic mixed convection heat and mass transfer through porous media. Another contribution to the theme of Dufour and Soret effects can be found in the paper by Afify [25], where there is a non-Darcy free convection past a vertical surface with temperature viscosity. 
Narayana and Murthy [26] studied the Soret and Dufour effects in a doubly stratified Darcy porous medium. Postelnicu [27] studied the influence of chemical reactions along with Soret and Dufour's effect in the absence of magnetic field on free convection. Singh and Chandarki [28] used integral treatment to obtain the expressions for Nusselt number and Sherwood number. El-Arabawy [29] studied the Soret and Dufour effects in a vertical plate with variable surface temperature. Postelnicu [30] analyzed the effect of Soret and Dufour on heat and mass transfer at a stagnation point. Tak et al. [31] investigated the MHD free convection-radiation in the presence of Soret and Dufour. Vempati and Laxmi-Narayana-Gari [32] studied the Soret and Dufour on MHD with thermal radiation. Recently, Cheng [33] studied the Soret and Dufour on heat and mass transfer on a vertical truncated cone with variable wall temperature and concentration. The aim of this paper is to study the effect of Soret and Dufour on heat and mass transfer by natural convection from a vertical plate with variable viscosity.

\section{Analysis}

Consider a vertical surface embedded in a saturated porous medium. The properties of the fluid and porous medium are isotropic, and the viscosity of the fluid is assumed to be an inverse linear function of temperature. Using Boussinesq and boundary layer approximations, the governing equations of continuity, momentum, energy, and concentration are given by

$$
\begin{gathered}
\frac{\partial u}{\partial x}+\frac{\partial v}{\partial y}=0 \\
u=-\frac{\kappa}{\mu}\left(\frac{\partial p}{\partial x}+\rho g\right), \\
v=-\frac{\mathcal{k}}{\mu}\left(\frac{\partial p}{\partial y}\right), \\
u \frac{\partial T}{\partial x}+v \frac{\partial T}{\partial y}=\alpha \frac{\partial^{2} T}{\partial y^{2}}+\frac{D_{m} k_{T}}{c_{s} c_{p}} \frac{\partial^{2} c}{\partial y^{2}} \\
u \frac{\partial c}{\partial x}+v \frac{\partial c}{\partial y}=D_{m} \frac{\partial^{2} c}{\partial y^{2}}+\frac{D_{m} k_{T}}{T_{m}} \frac{\partial^{2} T}{\partial y^{2}}, \\
\rho=\rho_{\infty}\left\{1-\beta\left(T-T_{\infty}\right)-\beta^{*}\left(c-c_{\infty}\right)\right\} .
\end{gathered}
$$

The viscosity of the fluid is assumed to be an inverse linear function of temperature, and it can be expressed as

$$
\frac{1}{\mu}=\frac{1}{\mu_{\infty}}\left\{1+\gamma\left(T-T_{\infty}\right)\right\},
$$

which is reasonable for liquids such as water and oil. Here, $\gamma$ is a constant. The boundary conditions are

$$
\begin{aligned}
& y=0, \quad v=0, \quad T=T_{w}, \quad c=c_{w}, \\
& y \longrightarrow \infty, \quad u=0, \quad T=T_{\infty}, \quad c=c_{\infty} \text {. }
\end{aligned}
$$




\section{Method of Solution}

Introducing the stream function $\Psi(x, y)$ such that

$$
u=\frac{\partial \psi}{\partial y}, \quad v=-\frac{\partial \psi}{\partial x}
$$

where

$$
\begin{gathered}
\psi=\alpha f\left(\operatorname{Ra}_{x}\right)^{1 / 2}, \\
\eta=\frac{y}{x}\left(\operatorname{Ra}_{x}\right)^{1 / 2}, \\
\operatorname{Ra}_{x}=\left\{\frac{k g \beta \Delta T x}{v \alpha}\right\}, \quad \text { is the Rayleigh number }
\end{gathered}
$$

Define

$$
\begin{gathered}
\theta=\frac{T-T_{\infty}}{T_{w}-T_{\infty}}, \\
\phi=\frac{c-c_{\infty}}{c_{w}-c_{\infty}}, \\
N=\frac{\beta^{*}\left(c_{w}-c_{\infty}\right)}{\beta\left(T_{w}-T_{\infty}\right)} .
\end{gathered}
$$

Substituting these transformations (3.1) to (3.7) to Equations (2.2) to (2.5) along with (2.6) and (2.7), the resulting nonlinear ordinary differential equations are

$$
\begin{gathered}
f^{\prime \prime}=\frac{f^{\prime} \theta^{\prime}}{\theta-\theta_{r}}-\left(\frac{\theta-\theta_{r}}{\theta_{r}}\right)\left(\theta^{\prime}+\phi^{\prime} N\right), \\
\theta^{\prime \prime}+\operatorname{Pr} \operatorname{Du} \phi^{\prime \prime}+\frac{1}{2} f \theta^{\prime}=0, \\
\phi^{\prime \prime}+\operatorname{ScSr} \theta^{\prime \prime}+\frac{\operatorname{Le}}{2} f \phi^{\prime}=0,
\end{gathered}
$$

together with the boundary conditions

$$
\begin{array}{cccc}
\eta=0, & f=0, & \theta=1, & \phi=1, \\
\eta \longrightarrow \infty, & f^{\prime}=0, & \theta=0, & \phi=0,
\end{array}
$$

where $\operatorname{Pr}=v / \alpha$ is the Prandtl number, $\mathrm{Du}=D_{m} k_{T}\left(c_{w}-c_{\infty}\right) / c_{s} c_{p} v\left(T_{w}-T_{\infty}\right)$ is the Dufour number, $\mathrm{Sc}=v / D_{m}$ is the Schmidt number, $\mathrm{Sr}=D_{m} k_{T}\left(T_{w}-T_{\infty}\right) / T_{m} v\left(c_{w}-c_{\infty}\right)$ is the Soret number, Le $=\alpha / D_{m}$ is the Lewis number, and $\theta_{r}=-1 / \gamma\left(T_{w}-T_{\infty}\right)$ is the parameter characterizing the influence of viscosity. For a given temperature differential, large values of 


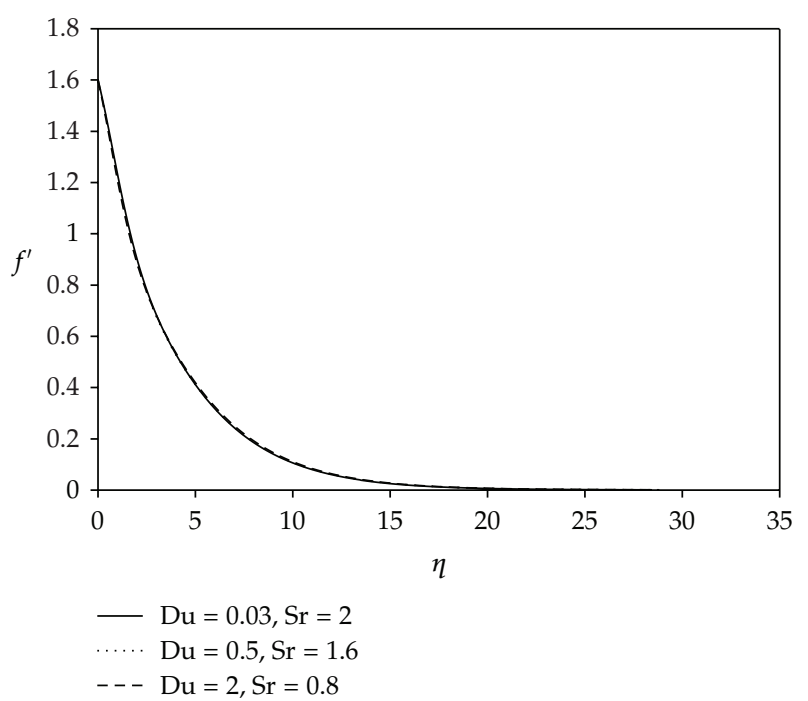

Figure 1: Velocity profile for different values of Dufour and Soret for $\theta_{r}=5, N=1$, Le $=0.1, \operatorname{Pr}=0.71$, and $\mathrm{Sc}=0.1$.

$\theta_{r}$ imply that either $\gamma$ or $\left(T_{w}-T_{\infty}\right)$ is small. In this case, the effect of variable viscosity can be neglected.

The effect of variable viscosity is important if $\theta_{r}$ is small. Since the viscosity of liquids decreases with increasing temperature while it increases for gases, $\theta_{r}$ is negative for liquids and positive for gases. The concept of this parameter $\theta_{r}$ was first introduced by Ling and Dybbs [34] in their study of forced convection flow in porous media. The parameter $N$ measures the relative importance of mass and thermal diffusion in the buoyancy-driven flow. It is clear that $N$ is zero for thermal-driven flow, infinite for mass-driven flow, positive for aiding flow, and negative for opposing flow.

\section{Numerical Analysis and Discussion}

Equations (3.8), (3.9), and (3.10) are integrated numerically by using Runge-Kutta-Gill method along with shooting technique. The parameters involved in this problem are $\theta_{r}$ : the variable viscosity, Le: Lewis number, $N$ : the buoyancy parameter, Pr: Prandtl number, Du: Dufour number, Sr: Soret number, and Sc: Schmidt number. To observe the effect of variable viscosity on heat and mass transfer, we have plotted the velocity function $f^{\prime}$, temperature function $\theta$, and the concentration function $\Phi$ against $\eta$ for various values of $\theta_{r}$, Le, and $N$. The value of Prandtl number Pr is taken equal to 0.71 which corresponds to air. The values of the Dufour number and Soret number are taken in such a way that their product is constant according to their definition provided that the mean temperature is kept constant as well. The parameter $\theta_{r}$ is used to represent the effect of variable viscosity. The case $\theta_{r}<0$ corresponds to the case of liquids, and $\theta_{r}>0$ corresponds to the case of gases.

The influence of Dufour number Du and Soret number Sr on velocity, temperature, and concentration profiles is shown in Figures 1, 2, and 3, respectively, for $\theta_{r}=5, N=1$, $\mathrm{Le}=0.1, \operatorname{Pr}=.71$, and $\mathrm{Sc}=0.1$. Figure 1 shows that as Dufour number increases, the velocity decreases slightly for decrease in Soret number. From Figure 2, it is evident that as Dufour 


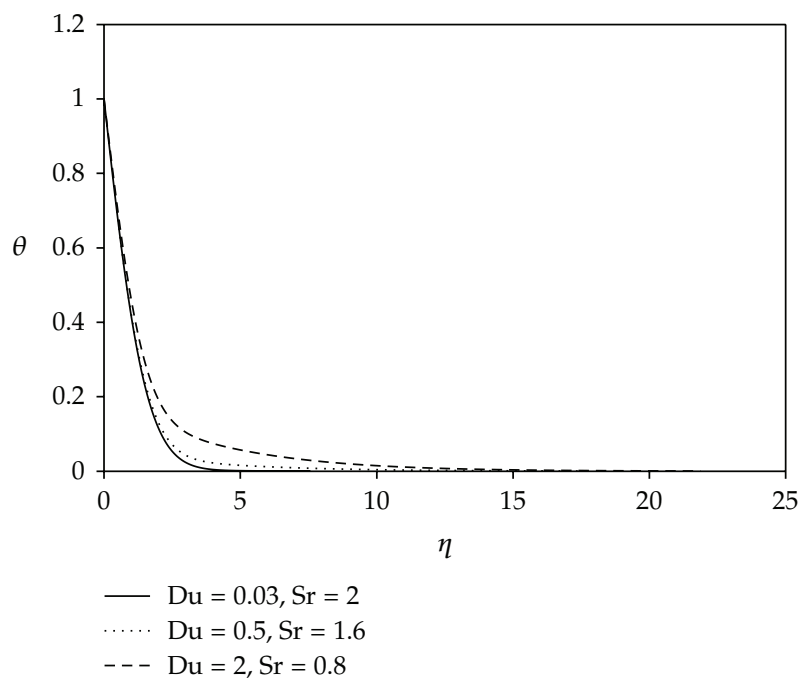

Figure 2: Temperature profile for different values of Dufour and Soret for $\theta_{r}=5, N=1, \operatorname{Le}=0.1, \operatorname{Pr}=0.71$, and $S_{c}=0.1$.

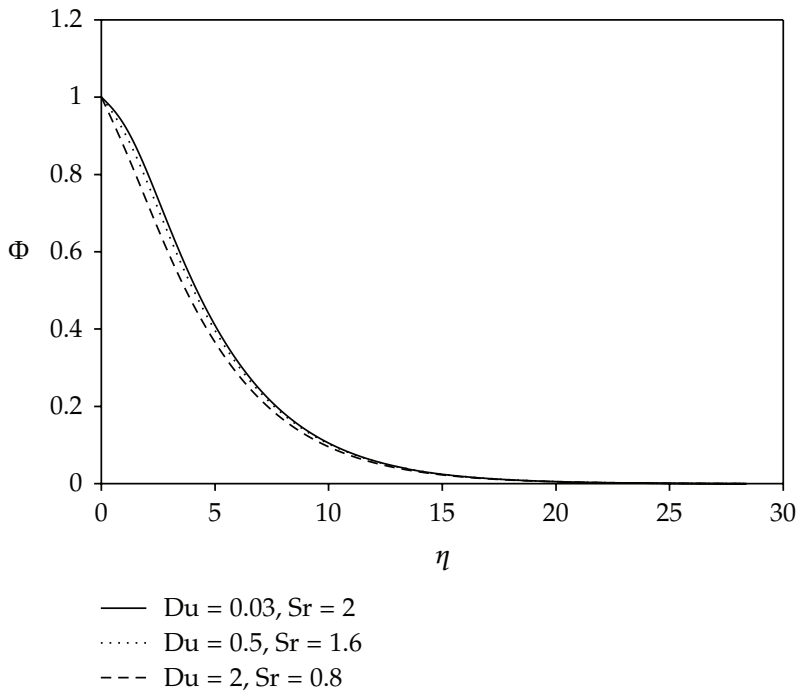

Figure 3: Concentration profile for different values of Dufour and Soret for $\theta_{r}=5, N=1$, Le $=0.1$, $\operatorname{Pr}=0.71$, and $\mathrm{Sc}=0.1$.

number increases, the temperature increases for decrease in Soret number. Figure 3 shows that as Dufour number increases, the concentration decreases for decrease in Soret number.

The effect of variable viscosity $\theta_{r}$ on velocity, temperature, and concentration is shown in Figures 4, 5, and 6, respectively, for $N=1, \mathrm{Le}=0.1, \mathrm{Pr}=.71, \mathrm{Sc}=0.1, \mathrm{Du}=0.03$, and $\mathrm{Sr}=2$. From Figure 4 , it is realized that the velocity increases near the plate and decreases away from the plate as $\theta_{r} \rightarrow 0$ in the case of liquids $\left(\theta_{r}<0\right)$ and decreases near the plate and increases away from the plate as $\theta_{r} \rightarrow 0$ in the case of gases $\left(\theta_{r}>0\right)$. From Figures 5 and 6 , it is 


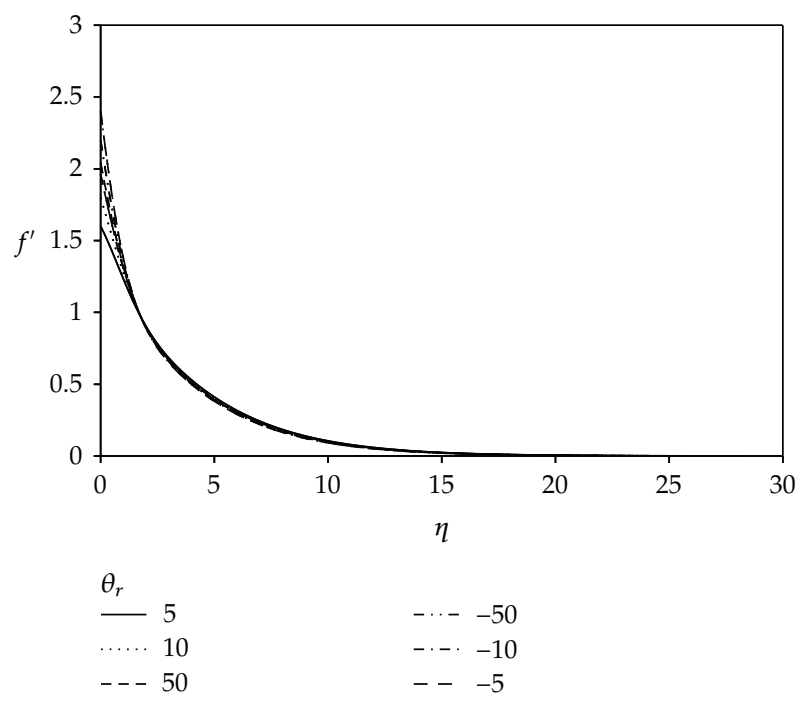

Figure 4: Velocity profile for different values of $\theta_{r}$ for $\mathrm{Du}=0.03, \mathrm{Sr}=2, N=1$, Le $=0.1, \operatorname{Pr}=0.71$, and $\mathrm{Sc}=0.1$.

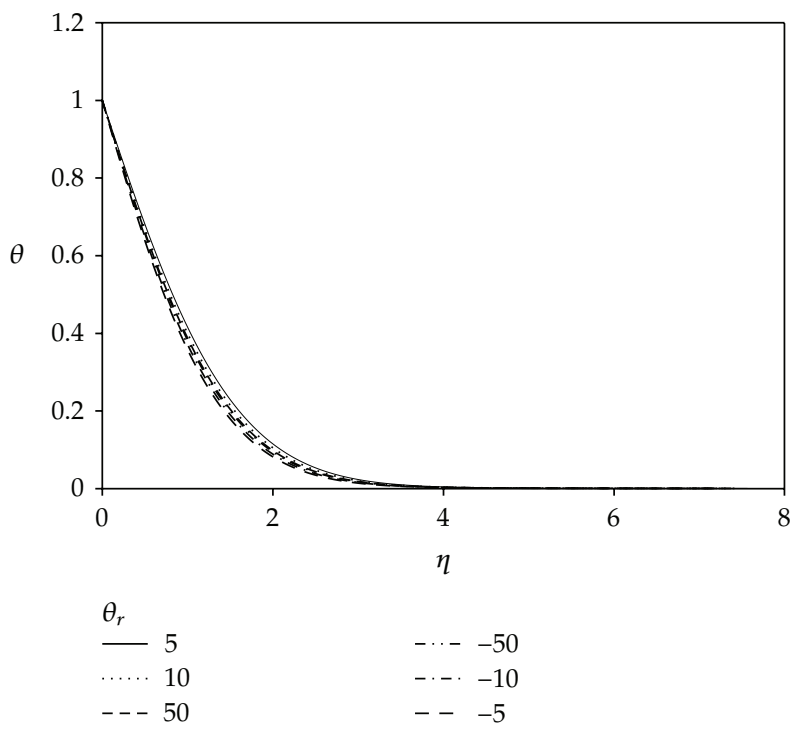

Figure 5: Temperature profile for different values of $\theta_{r}$ for $\mathrm{Du}=0.03, \mathrm{Sr}=2, N=1, \mathrm{Le}=0.1, \operatorname{Pr}=0.71$, and $\mathrm{Sc}=0.1$.

evident that the temperature and concentration increase as $\theta_{r} \rightarrow 0$ for $\theta_{r}>0$ (i.e., for gases) and decrease as $\theta_{r} \rightarrow 0$ for $\theta_{r}<0$ (i.e., for liquids).

The effect of buoyancy ratio $N$ on velocity, temperature, and concentration is shown in Figures 7, 8, and 9, respectively, for $\theta_{r}=5, \mathrm{Le}=0.1$, and $\mathrm{Pr}=.71$ and $\mathrm{Sc}=0.1, \mathrm{Du}=0.03$, and $\mathrm{Sr}=2$. From Figure 7 , it is observed that the velocity increases near the plate and decreases 


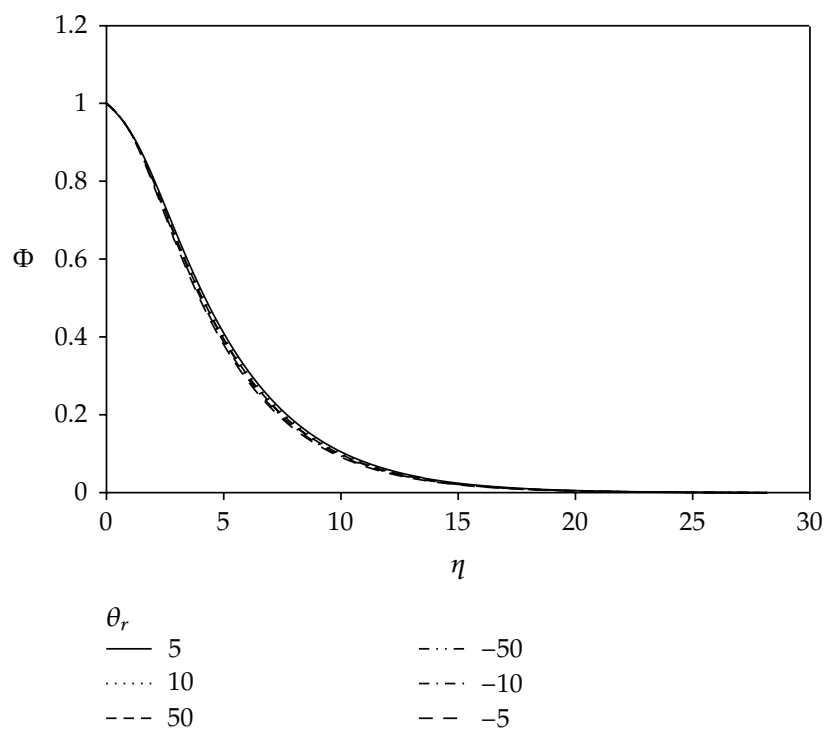

Figure 6: Concentration profile for different values of $\theta_{r}$ for $\mathrm{Du}=0.03, \mathrm{Sr}=2, N=1, \mathrm{Le}=0.1, \operatorname{Pr}=0.71$, and $\mathrm{Sc}=0.1$.

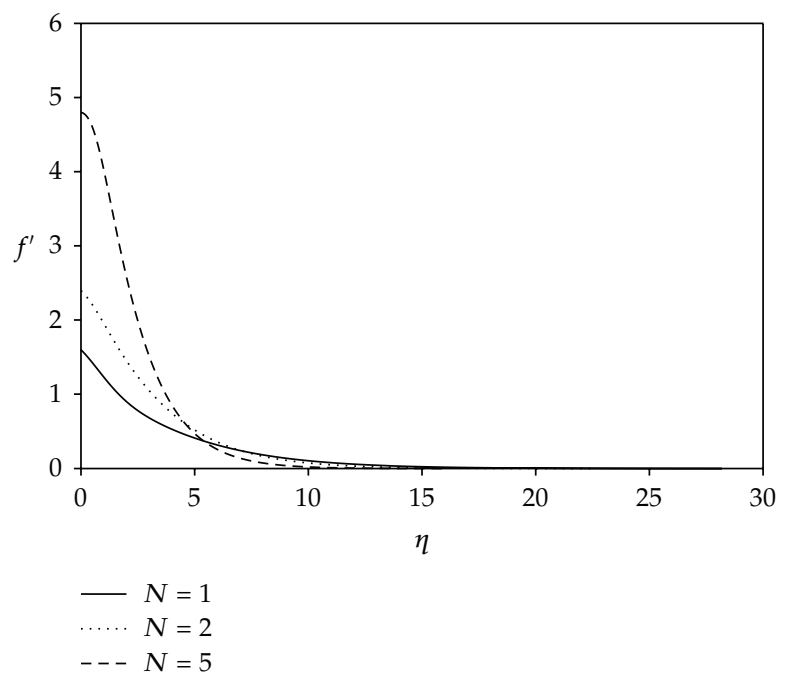

Figure 7: Velocity profile for different values of $N$ for $\mathrm{Du}=0.03, \mathrm{Sr}=2, \theta_{r}=5$, Le $=0.1, \operatorname{Pr}=0.71$, and Sc $=0.1$.

away from the plate as $N$ increases. From Figures 8 and 9, it is realized that the temperature and concentration decrease as $N$ increases.

The effect of Lewis number Le on temperature and concentration is shown in Figures 10 and 11, respectively, for $N=1, \operatorname{Pr}=.71, \mathrm{Sc}=0.1, \mathrm{Du}=0.03, \mathrm{Sr}=2$, and for different values of $\theta_{r}$ and Le. From Figure 10, it is observed that as Le increases, the heat 


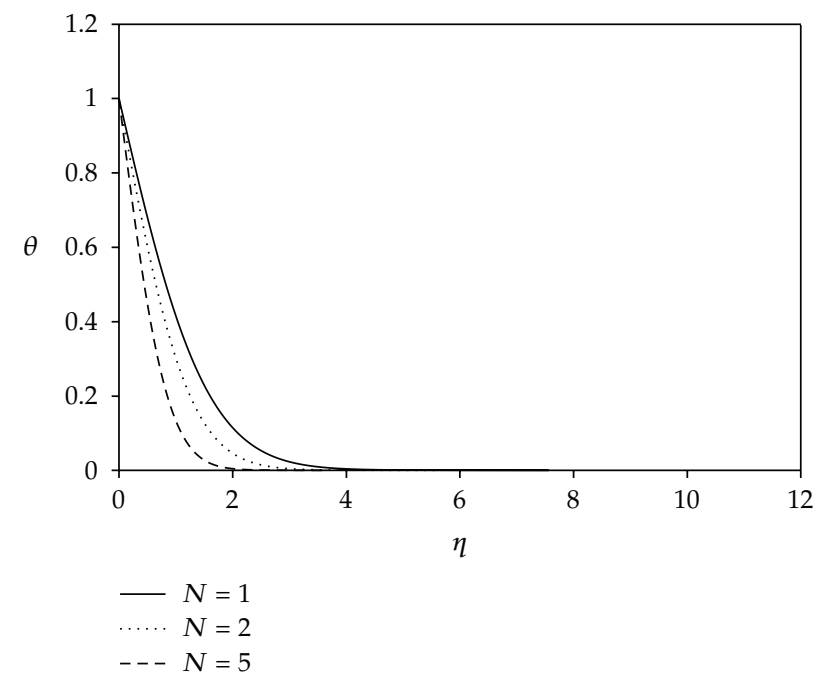

Figure 8: Temperature profile for different values of $N$ for $\mathrm{Du}=0.03, \mathrm{Sr}=2, \theta_{r}=5, \mathrm{Le}=0.1, \mathrm{Pr}=0.71$, and $\mathrm{Sc}=0.1$.

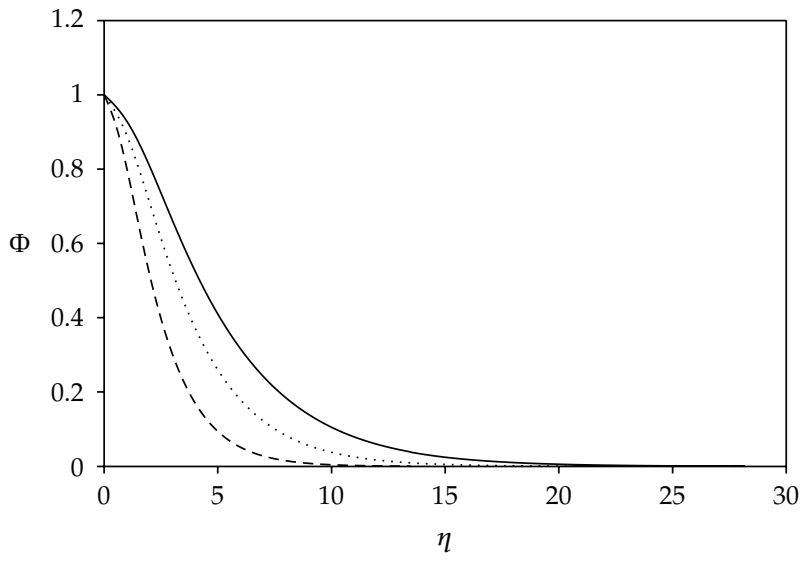

$$
\begin{aligned}
-N & =1 \\
\cdots \cdots & N=2 \\
--N & =5
\end{aligned}
$$

Figure 9: Concentration profile for different values of $N$ for $\mathrm{Du}=0.03, \mathrm{Sr}=2, \theta_{r}=5, \mathrm{Le}=0.1, \mathrm{Pr}=0.71$, and $S_{c}=0.1$.

transfer decreases for both $\theta_{r}>0$ and $\theta_{r}<0$. From Figure 11, it is realized that as Le increases, the mass transfer increases for both $\theta_{r}>0$ and $\theta_{r}<0$.

The effect of Prandtl number Pr on velocity, temperature, and concentration is shown in Figures 12, 13, and 14, respectively, for $N=1, \mathrm{Sc}=0.1, \mathrm{Du}=0.03, \mathrm{Sr}=2, \mathrm{Le}=0.1$, and $\theta_{r}=5$. From Figures 12 and 13, it is evident that as the Prandtl number increases, the velocity and temperature increase. Figure 14 shows that as the prandtl number increases, the concentrations decrease. 


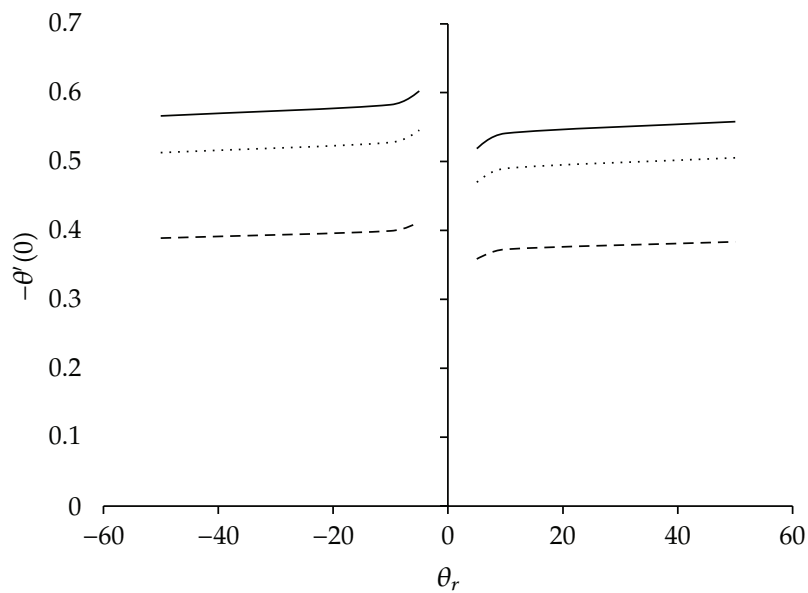

- - - Le $=3$

…. $\mathrm{Le}=7$

- Le $=50$

Figure 10: Effect of Lewis number Le on the rate of heat transfer for different values of $\theta_{r}$ for Du $=0.03$, $\mathrm{Sr}=2, N=1, \operatorname{Pr}=0.71$, and $\mathrm{Sc}=0.1$.

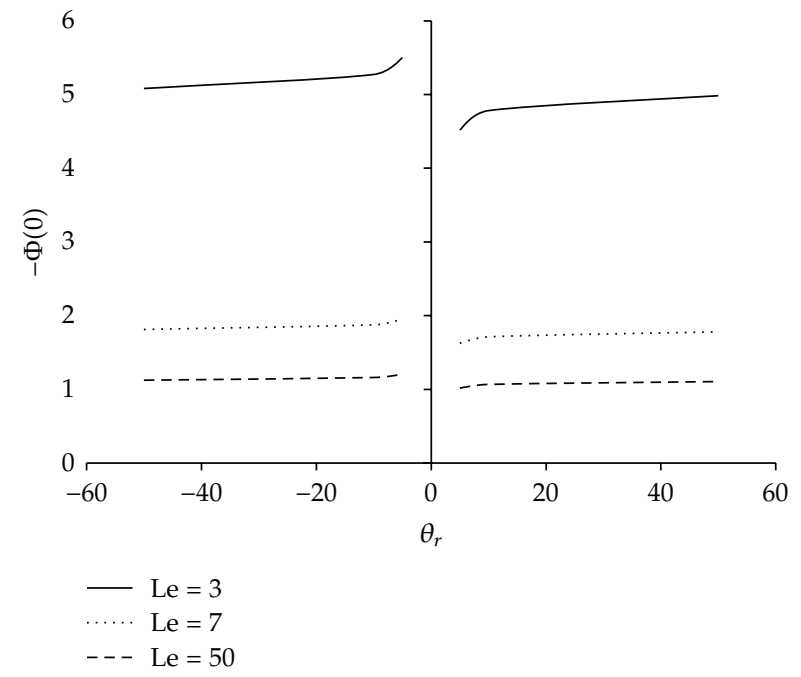

Figure 11: Effect of Lewis number Le on the rate of mass transfer for different values of $\theta_{r}$ for Du $=0.03$, $\mathrm{Sr}=2, N=1, \operatorname{Pr}=0.71$, and $\mathrm{Sc}=0.1$.

The parameters of engineering interests for the present problem are the local Nusselt number $\mathrm{Nu}_{x}$ and Sherwood number $\mathrm{Sh}_{x}$, which are given by

$$
\begin{aligned}
& \frac{\mathrm{Nu}_{x}}{\left(\mathrm{Ra}_{x}\right)^{1 / 2}}=-\theta^{\prime}(0), \\
& \frac{\mathrm{Sh}_{x}}{\left(\mathrm{Ra}_{x}\right)^{1 / 2}}=-\phi^{\prime}(0) .
\end{aligned}
$$




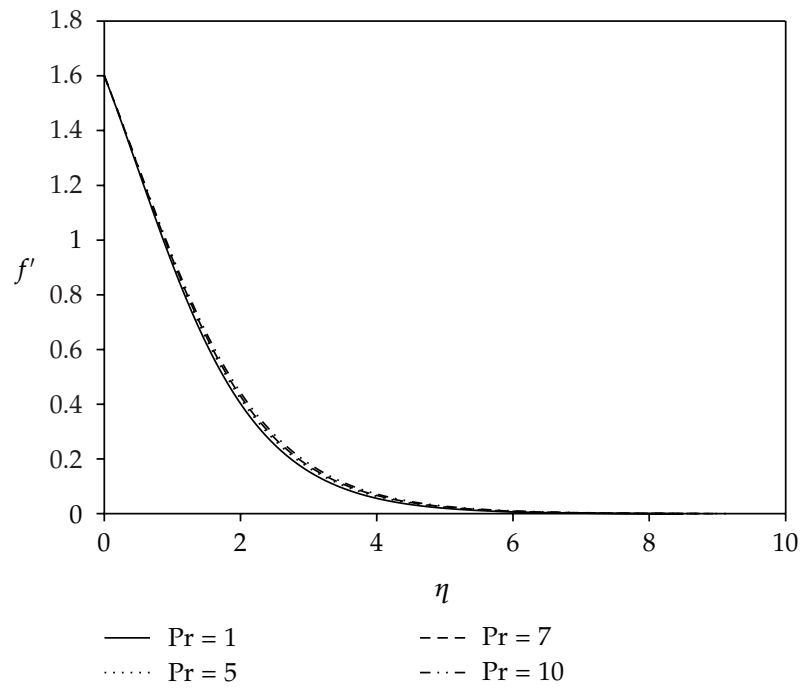

Figure 12: Velocity profile for different values of $\operatorname{Pr}$ for $\mathrm{Du}=0.03, \mathrm{Sr}=2, \theta_{r}=5$, Le $=0.1, N=1$, and $\mathrm{Sc}=0.1$.

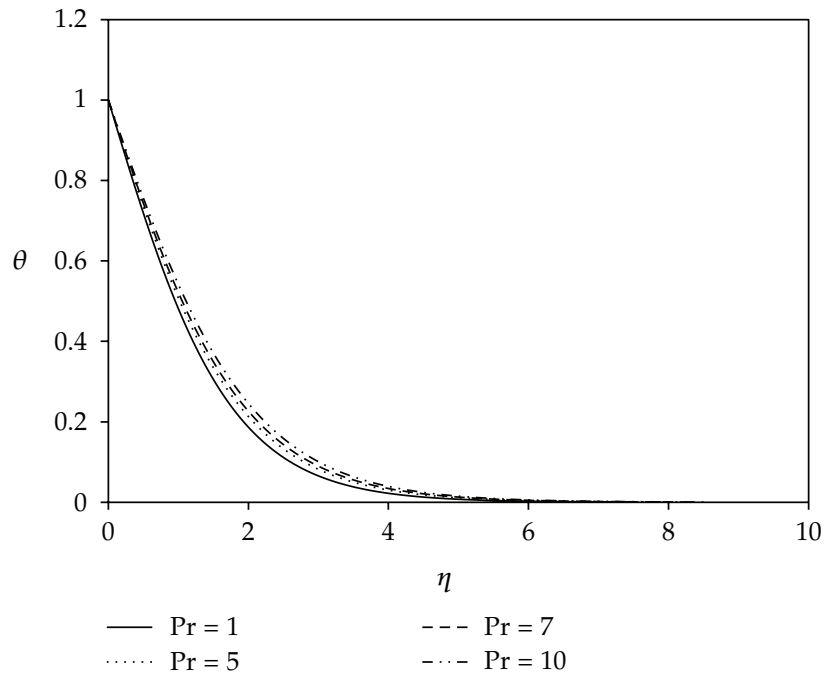

Figure 13: Temperature profile for different values of $\operatorname{Pr}$ for $\mathrm{Du}=0.03, \mathrm{Sr}=2, \theta_{r}=5, \mathrm{Le}=0.1, N=1$, and Sc $=0.1$.

The values of Nusselt number and Sherwood number for different values of variable viscosity $\theta_{r}$ and the buoyancy ratio $N$ are presented in Table 1 for $\mathrm{Le}=0.1, \mathrm{Sc}=0.1, \mathrm{Du}=0.03$, $\mathrm{Sr}=2$, and $\operatorname{Pr}=.71$. It is evident that as $\theta_{r} \rightarrow 0$ for $\theta_{r}>0$, the Nusselt number decreases and the Sherwood number increases. It is also realized that as $\theta_{r} \rightarrow 0$ for $\theta_{r}<0$, the Nusselt number increases and the Sherwood number decreases for other parameters fixed. 


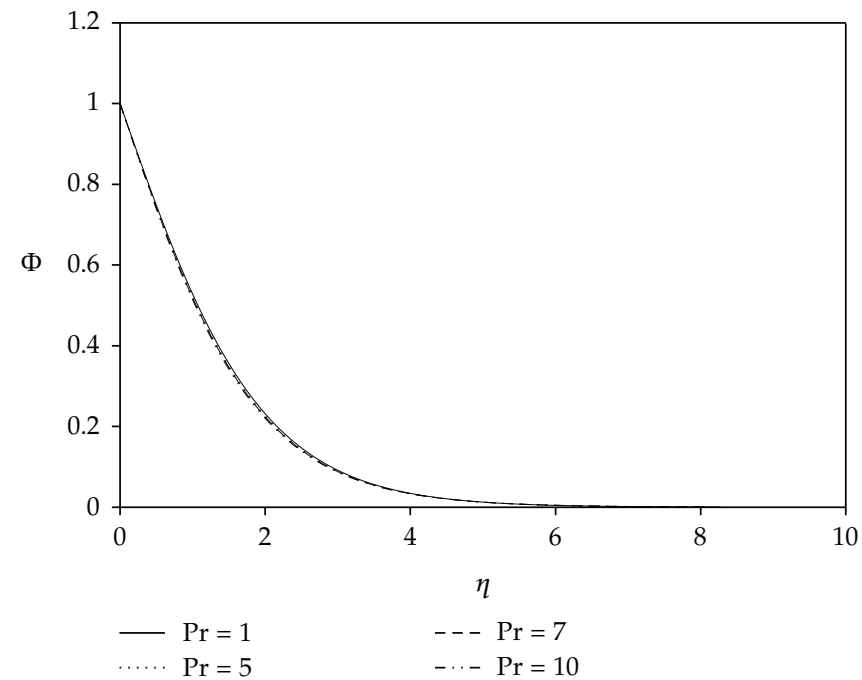

Figure 14: Concentration profile for different values of $\operatorname{Pr}$ for $\mathrm{Du}=0.03, \mathrm{Sr}=2, \theta_{r}=5, \mathrm{Le}=0.1, N=1$, and Sc $=0.1$.

Table 1: Numerical values of Nusselt and Sherwood numbers for various values of $N$ and $\theta_{r}$ for Le $=0.1$, $\mathrm{Du}=0.03, \mathrm{Sr}=2, N=1$, and $\mathrm{Sc}=0.1$.

\begin{tabular}{|c|c|c|c|c|c|c|}
\hline \multicolumn{4}{|c|}{ Nusselt number } & \multicolumn{3}{|c|}{ Sherwood number } \\
\hline \multirow{2}{*}{$\theta_{r}$} & \multicolumn{6}{|c|}{$N$} \\
\hline & 1 & 2 & 5 & 1 & 2 & 5 \\
\hline 5 & -0.6589 & -0.8335 & -1.2140 & -0.0571 & -0.0841 & -0.1363 \\
\hline 10 & -0.6848 & -0.8658 & -1.2605 & -0.0556 & -0.0825 & -0.1343 \\
\hline 50 & -0.7047 & -0.8907 & -1.2965 & -0.0544 & -0.0812 & -0.1326 \\
\hline-5 & -0.7568 & -0.9558 & -1.3903 & -0.0514 & -0.0779 & -0.1283 \\
\hline-10 & -0.7336 & -0.9268 & -1.3480 & -0.0528 & -0.0794 & -0.1303 \\
\hline-50 & -0.7145 & -0.9029 & -1.3140 & -0.0539 & -0.0806 & -0.1318 \\
\hline
\end{tabular}

\section{Conclusion}

The Dufour and Soret effect on free convective heat and mass transfer flow past a semiinfinite vertical plate under the influence of variable viscosity has been studied. Using usual similarity transformations, the governing equations have been transformed into nonlinear ordinary differential equations. The similarity solutions are obtained numerically by applying Runge-Kutta-Gill method along with shooting technique. The effects of the variable viscosity parameter $\theta_{r}$, the Lewis number Le, the buoyancy ratio $N$, the Dufour number $\mathrm{Du}$, the Soret number Sr, the prandtl number Pr, and the Schmidt number Sc on the velocity, temperature, and concentration profiles are examined. From the present study, we see that the thermal and species concentration boundary layer thickness increases for gases and decreases for liquids. 


\section{Nomenclature}

$c$ : Concentration at any point in the flow field

$c_{p}$ : Specific heat at constant pressure

$c_{s}$ : Concentration susceptibility

$c_{w}$ : Concentration at the wall

$c_{\infty}$ : Concentration at the free stream

$D_{m}$ : Mass diffusivity

Du: Dufour number

$f$ : Dimensionless velocity function

g: Acceleration due to gravity

$k$ : Permeability

$k_{T}$ : Thermal diffusion ratio

Le: Lewis number $\left[\mathrm{Le}=\alpha / D_{m}\right]$

$N$ : Buoyancy ratio $\left[N=\beta^{*}\left(c_{w}-c_{\infty}\right) / \beta\left(T_{w}-T_{\infty}\right)\right]$

$\mathrm{Nu}_{x}$ : Nusselt number $\left[\mathrm{Nu}_{x}=-x(\partial T / \partial y)_{y=0} /\left(T_{w}-T_{\infty}\right)\right]$

$p$ : Pressure

Pr: Prandtl number

$\mathrm{Ra}_{x}$ : Rayleigh number $\mathrm{Ra}_{x}=[k g \beta \Delta T x / v \alpha]$

Sc: Schmidt number

$\mathrm{Sh}_{x}$ : Sherwood number $\left[\mathrm{Sh}_{x}=m x / D\left(c_{w}-c_{\infty}\right)\right]$

Sr: Soret number

$T$ : Temperature of the fluid

$T_{w}$ : Temperature of the plate

$T_{\infty}$ : Temperature of the fluid far from the plate

$u, v$ : Velocity components in $x$ and $y$ direction

$x, y$ : Coordinate system.

\section{Greek Letters}

$\alpha$ : Thermal diffusivity

$\beta$ : Coefficient of thermal expansion

$\beta^{*}$ : Concentration expansion coefficient

$\gamma$ : Constant defined in (2.7)

$\eta$ : Dimensionless similarity variable

$\theta$ : Dimensionless temperature

$\theta_{r}:-1 / \gamma\left(T_{w}-T_{\infty}\right)$

$\mu$ : Viscosity [pas]

$v$ : Kinematic viscosity

$\rho$ : Density

$\Phi:$ Dimensionless concentration

$\psi$ : Dimensionless stream function.

\section{Acknowledgments}

The authors tender their heartfelt thanks to Dr. T. Govindarajulu the former Professor and Head of the Department of Mathematics, Anna University, Chennai, for his generous help. 
The authors wish to thank the Director and the Principal of IRTT for their kind support. The authors also wish to thank Dr. K. Thyagarajah, The Principal, K. S. Rangasamy College of Technology, for his help and guidance to do this work.

\section{References}

[1] I. Pop. and D. B. Ingham, Convective Heat Transfer: Mathematical and Computational Modeling of Viscous Fluids and Porous Media, Pergamon, Oxford, UK, 2001.

[2] D. B. Ingham and I. Pop, Transport Phenomena in Porous Media III, Elsevier, Oxford, UK, 2005.

[3] K. Vafai, Handbook of Porous Media, Taylor and Francis, New York, NY, USA, 2nd edition, 2005.

[4] E. R. G. Eckert and R. M. Drake, Analysis of Heat and Mass Transfer, McGraw-Hill, New York, NY, USA, 1972.

[5] D. R. Kassoy and A. Zebib, "Variable viscosity effects on the onset of convection in porous media," Physics of Fluids, vol. 18, no. 12, pp. 1649-1651, 1975.

[6] P. Cheng and W. J. Minkowycz, "Free convection about a vertical plate embedded in a porous medium with application to heat transfer from a dike," Journal of Geophysical Research, vol. 82, no. 14, pp. 20402044, 1977.

[7] A. Bejan and K. R. Khair, "Heat and mass transfer by natural convection in a porous medium," International Journal of Heat and Mass Transfer, vol. 28, no. 5, pp. 909-918, 1985.

[8] F. C. Lai and F. A. Kulacki, "The effect of variable viscosity on convective heat transfer along a vertical surface in a saturated porous medium," International Journal of Heat and Mass Transfer, vol. 33, no. 5, pp. 1028-1031, 1990.

[9] F. C. Lai and F. A. Kulacki, "Coupled heat and mass transfer by natural convection from vertical surfaces in porous media," International Journal of Heat and Mass Transfer, vol. 34, no. 4-5, pp. 1189-1194, 1991.

[10] E. M. A. Elbashbeshy and F. N. Ibrahim, "Steady free convection flow with variable viscosity and thermal diffusivity along a vertical plate," Journal of Physics D, vol. 26, no. 12, pp. 2137-2143, 1993.

[11] N. G. Kafoussias and E. W. Williams, "Thermal-diffusion and diffusion-thermo effects on mixed freeforced convective and mass transfer boundary layer flow with temperature dependent viscosity," International Journal of Engineering Science, vol. 33, no. 9, pp. 1369-1384, 1995.

[12] K. A. Yih, "Coupled heat and mass transfer in mixed convection over a wedge with variable wall temperature and concentration in porous media: the entire regime," International Communications in Heat and Mass Transfer, vol. 25, no. 8, pp. 1145-1158, 1998.

[13] R. Y. Jumah and A. S. Mujumdar, "Free convection heat and mass transfer of non-Newtonian power law fluids with yield stress from a vertical flat plate in saturated porous media," International Communications in Heat and Mass Transfer, vol. 27, no. 4, pp. 485-494, 2000.

[14] M. Anghel, H. S. Takhar, and I. Pop, Dufour and Soret Effects on Free Convection Boundary Layer Over a Vertical Surface Embedded in a Porous Medium, Studia Universitatis Babes-Bolyai, 2000, Mathematica XLV: 11-22.

[15] M. Kumari, "Variable viscosity effects on free and mixed convection boundary-layer flow from a horizontal surface in a saturated porous medium-variable heat flux," Mechanics Research Communications, vol. 28, no. 3, pp. 339-348, 2001.

[16] A. Postelnicu, T. Grosan, and I. Pop, "The effect of variable viscosity on forced convection flow past a horizontal flat plate in a porous medium with internal heat generation," Mechanics Research Communications, vol. 28, no. 3, pp. 331-337, 2001.

[17] M. A. Seddeek, "Finite element method for the effects of chemical reaction, variable viscosity, thermophoresis and heat generation/ absorption on a boundary layer hydro magnetic flow with heat and mass transfer over a heat surface," Acta Mechanica, vol. 177, pp. 1-18, 2005.

[18] M. A. Seddeek and A. M. Salem, "Laminar mixed convection adjacent to vertical continuously stretching sheets with variable viscosity and variable thermal diffusivity," International Journal of Heat and Mass Transfer, vol. 41, no. 12, pp. 1048-1055, 2005.

[19] M. E. Ali, "The effect of variable viscosity on mixed convection heat transfer along a vertical moving surface," International Journal of Thermal Sciences, vol. 45, no. 1, pp. 60-69, 2006.

[20] M. S. Alam, M. M. Rahman, and M. A. Samad, "Numerical study of the combined free-forced convection and Mass transfer flow past a vertical porous plate in a porous medium with heat 
generation and thermal diffusion," Non linear Analysis Modeling and Control, vol. 11, no. 4, pp. 331-343, 2006.

[21] A. Pantokratoras, "The Falkner-skan flow with constant wall temperature and variable viscosity," International Journal of Thermal Sciences, vol. 45, no. 4, pp. 378-389, 2006.

[22] M. K. Partha, P. V. S. N. Murthy, and G. P. R. Sekhar, "Soret and Dufour effects in a non-Darcy porous medium," Journal of Heat Transfer, vol. 128, no. 6, pp. 605-610, 2006.

[23] M. S. Alam and M. M. Rahman, "Dufour and Soret effects on mixed convection flow past a vertical porous flat plate with variable suction," Nonlinear Analysis: Modelling and Control, vol. 11, no. 1, pp. 3-12, 2006.

[24] M. A. Seddeek, A. A. Darwish, and M. S. Abdelmeguid, "Effect of chemical reaction and variable viscosity on hydro magnetic mixed convection heat and mass transfer for Hiemenz flow through porous media with radiation," Communications in Nonlinear Science and Numerical Simulation, vol. 12, pp. 195-213, 2007.

[25] A. Afify, "Effects of thermal-diffusion and diffusion thermo on non-Darcy MHD free convective heat and mass transfer past a vertical isothermal surface embedded in a porous medium with thermal dispersion and temperature-dependent viscosity," Applied Mathematical Modelling, vol. 31, pp. 16211634, 2007.

[26] P. A. L. Narayana and P. V. S. N. Murthy, "Soret and dufour effects on free convection heat and mass transfer in a doubly stratified darcy porous medium," Journal of Porous Media, vol. 10, no. 6, pp. 613623, 2007.

[27] A. Postelnicu, "Influence of chemical reaction on heat and mass transfer by natural convection from vertical surfaces in porous media considering Soret and Dufour effects," Heat and Mass Transfer, vol. 43, no. 6, pp. 595-602, 2007.

[28] B. B. Singh and I. M. Chandarki, "Integral treatment of coupled heat and mass transfer by natural convection from a cylinder in porous media," International Communications in Heat and Mass Transfer, vol. 36, no. 3, pp. 269-273, 2009.

[29] H. A. M. El-Arabawy, "Soret and dufour effects on natural convection flow past a vertical surface in a porous medium with variable surface temperature," Journal of Mathematics and Statistics, vol. 5, no. 3, pp. 190-198, 2009.

[30] A. Postelnicu, "Heat and mass transfer by natural convection at a stagnation point in a porous medium considering Soret and Dufour effects," Heat and Mass Transfer, vol. 46, no. 8-9, pp. 831-840, 2010.

[31] S. S. Tak, R. Mathur, R. K. Gehlot, and A. Khan, "MHD free convection-radiation interaction along a vertical surface embedded in darcian porous medium in presence of soret and Dufour's effects," Thermal Science, vol. 14, no. 1, pp. 137-145, 2010.

[32] S. R. Vempati and A. B. Laxmi-Narayana-Gari, "Soret and Dufour effects on unsteady MHD flow past an infinite vertical porous plate with thermal radiation," Applied Mathematics and Mechanics, vol. 31, no. 12, pp. 1481-1496, 2010.

[33] C. Y. Cheng, "Soret and Dufour effects on heat and mass transfer by natural convection from a vertical truncated cone in a fluid-saturated porous medium with variable wall temperature and concentration," International Communications in Heat and Mass Transfer, vol. 37, no. 8, pp. 1031-1035, 2010.

[34] J. X. Ling and A. Dybbs, "Forced convection over a flat plate submersed in a porous medium: variable viscosity case ," in Proceedings of the American Society of Mechanical Engineers, New York, NY, USA, 1987, ASME paper 87-WA/HT-23. 


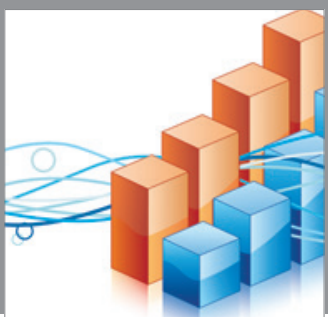

Advances in

Operations Research

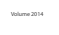

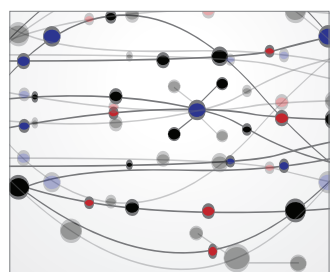

\section{The Scientific} World Journal
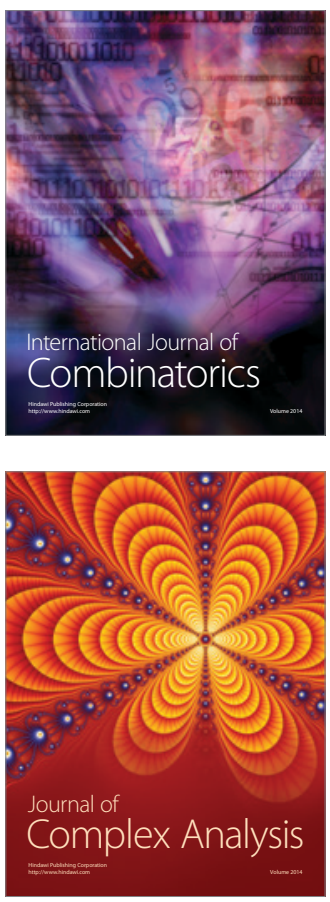

International Journal of

Mathematics and

Mathematical

Sciences
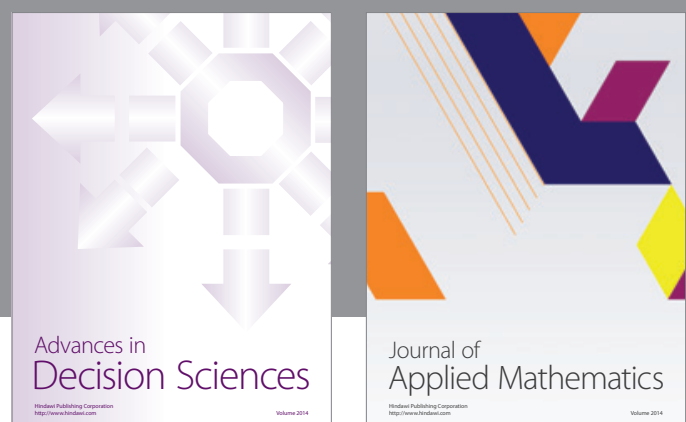

Journal of

Applied Mathematics
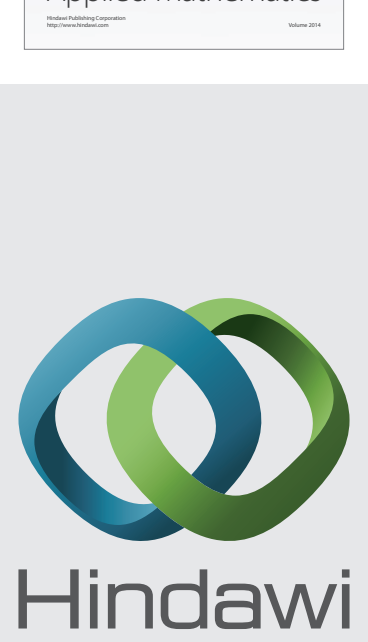

Submit your manuscripts at http://www.hindawi.com
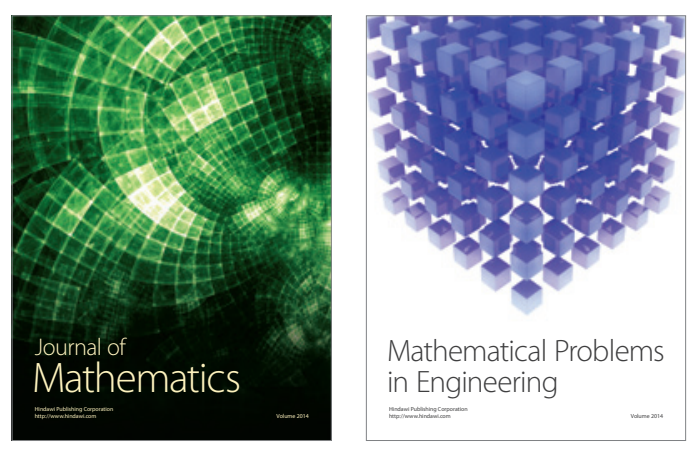

Mathematical Problems in Engineering
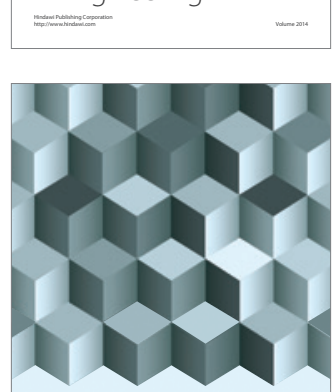

Journal of

Function Spaces
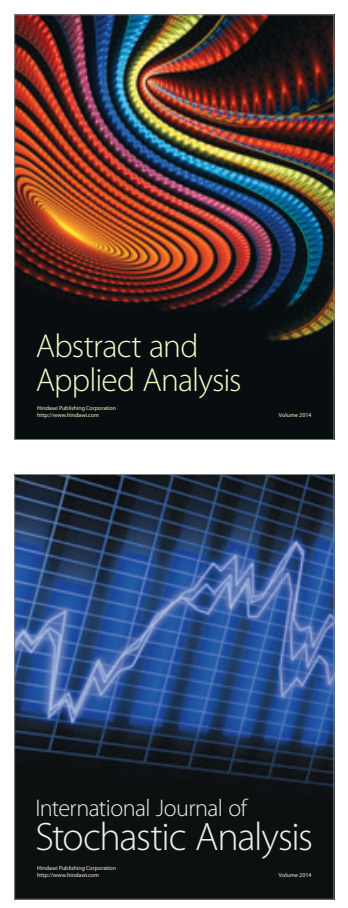

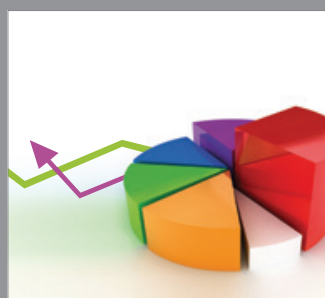

ournal of

Probability and Statistics

Promensencen
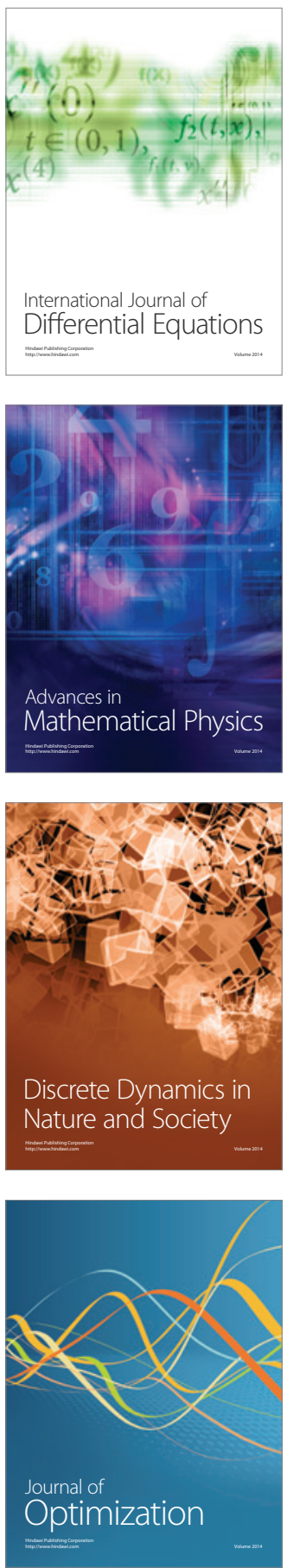